\title{
High-dose heparin is associated with higher bleeding and thrombosis rates in pediatric patients following cardiac surgery
}

\author{
Carina N. Vorisek, MD, ${ }^{a}$ Lynn A. Sleeper, ScD, ${ }^{\mathrm{b}, \mathrm{c}}$ Breanna Piekarski, MPH, ${ }^{\mathrm{a}}$ Minmin Lu, MS, ${ }^{\mathrm{b}}$ \\ Jenna Rogers, MPH, ${ }^{a}$ Olubunmi O. Oladunjoye, MBBS, ${ }^{a}$ and Sitaram M. Emani, MD ${ }^{\mathrm{a}, \mathrm{c}}$
}

\section{ABSTRACT}

Objective: To determine the association between unfractionated heparin (UFH) dose and the rate of postoperative bleeding and thrombosis events in pediatric cardiac patients. We tested the hypothesis that high-dose UFH is associated with higher rates of bleeding and thrombosis.

Methods: This is a retrospective review of pediatric patients admitted to the cardiac intensive care unit following cardiac surgery between November 2016 and December 2017. Peripheral venous thrombosis was excluded from analysis. Bleeding was defined as spontaneous bleeding remote from procedural manipulation. Postoperative UFH dosing strategy was categorized into 3 groups: no UFH, low-dose UFH $(<15 \mathrm{U} / \mathrm{kg} / \mathrm{h})$ and high-dose UFH $(\geq 15 \mathrm{U} / \mathrm{kg} / \mathrm{h})$. Statistical analysis was performed using multivariable logistic regression.

Results: We observed 966 consecutive patients (median age, 1.37 years; interquartile range, $0.27-5.50$ years) during their stay in the cardiac intensive care unit. There were 94 patients $(10 \%)$ with bleeding and 52 patients $(5 \%)$ with thrombosis during follow-up. Patients receiving high-dose UFH experienced significantly more bleeding (odds ratio, 2.35; 95\% confidence interval, 1.453.95 ) and thrombosis events (odds ratio, 3.65; 95\% confidence interval, 1.817.38) compared with patients receiving low-dose UFH. The odds of bleeding (odds ratio, 0.81; 95\% confidence interval, 0.45-1.47) and thrombosis (odds ratio, $0.59 ; 95 \%$ confidence interval, $0.26-1.35$ ) were similar in the low-dose UFH and no-UFH groups.

Conclusions: Bleeding remote from immediate postsurgical bleeding occurs uncommonly in pediatric patients following cardiac surgery. Anticoagulation with high-dose UFH is associated with higher bleeding rates as well as higher thrombosis rates. Indications for high-dose UFH should be carefully considered to reduce the rate of bleeding in this population. ( $\mathrm{J}$ Thorac Cardiovasc Surg 2019;158:1199-206)

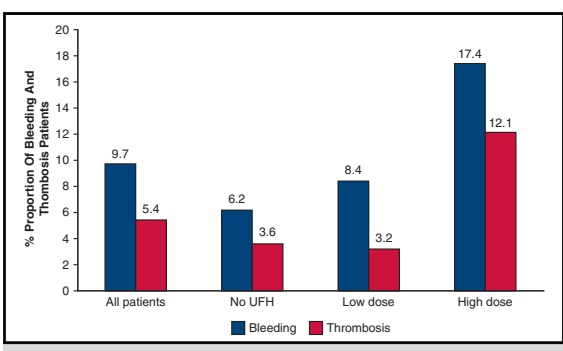

The high-dose UFH group had the highest proportion of bleeding and thrombosis patients.

\section{Central Message}

Anticoagulation with high dose UFH is associated with significantly higher bleeding and thrombosis rates in children following cardiac surgery.

\section{Perspective}

Indications for UFH use need to outweigh the risk for bleeding in pediatric patients after cardiac surgery. UFH doses $\geq 15 \mathrm{U} / \mathrm{kg} / \mathrm{h}$ are associated with higher rates of bleeding as well as more severe bleeds without sufficient protection against thrombosis

See Commentary on page 1207.

\footnotetext{
From the Departments of ${ }^{\mathrm{a} C}$ Cardiovascular Surgery and ${ }^{\mathrm{b}}$ Cardiology, Boston Children's Hospital, Boston, Mass; and ${ }^{\mathrm{c}}$ Department of Pediatrics, Harvard Medical School, Boston, Mass.

Supported by TEG plus Verify Now Coagulation Monitoring in the CICU (grant No. 2015-02), Goldwin Foundation, Lincoln, Neb.

Read at the 98th Annual Meeting of The American Association for Thoracic Surgery, San Diego, California, April 28-May 1, 2018.

Received for publication April 30, 2018; revisions received June 4, 2019; accepted for publication June 8, 2019; available ahead of print Aug 6, 2019.

Address for reprints: Sitaram M. Emani, MD, Department of Cardiovascular Surgery, Boston Children's Hospital, 300 Longwood Ave, Boston, MA 02115 (E-mail: Sitaram.Emani@cardio.chboston.org).

$0022-5223 / \$ 36.00$

Copyright (c) 2019 by The American Association for Thoracic Surgery

https://doi.org/10.1016/j.jtcvs.2019.06.015
}

Pediatric patients in the cardiac intensive care unit (CICU) are at high risk for bleeding and thrombosis events following cardiac surgery due to their cardiac pathology and state such as young age and comorbidities. ${ }^{1}$ The incidence of thrombosis events ranges from $11 \%$ to $20 \%$,

Scanning this QR code will
take you to the article title
page to access supplementary
information.




\section{Abbreviations and Acronyms \\ Anti-Xa $=$ antifactor Xa activity \\ aPTT = activated partial thromboplastin time \\ $\mathrm{CICU}=$ cardiac intensive care unit \\ UFH $=$ unfractionated heparin}

and complications from thrombosis events increase morbidity and mortality and are associated with catheter reintervention and reoperation. ${ }^{2}$ To prevent thrombosis, unfractionated heparin (UFH) is commonly used. In attempts to avoid thrombotic complications, many clinicians have adopted more liberal anticoagulation practices, including wider use of high-dose UFH for prophylaxis following cardiac surgical procedures deemed as high risk for thrombosis. However, this practice may increase the risk of bleeding complications in a vulnerable population of patients following major cardiac surgery. In addition, practice is primarily based on adult patient populations because there is a lack of guidelines or large pediatric clinical trials to inform indications for postoperative UFH therapy in pediatric patient populations. ${ }^{3}$ The effects of UFH therapy differ in pediatric patients relative to adults for many reasons, including different antithrombin III concentrations and different pharmacokinetics of UFH in the pediatric physiology. ${ }^{4}$ Still, monitoring UFH in pediatric patients is based on levels of activated partial thromboplastin time (aPTT) and antifactor Xa activity (anti-Xa) calculated from data on adult plasma. ${ }^{5}$ Because laboratory monitoring is limited in pediatric patients, we sought to determine UFH dosage regimens that prevent thrombosis events and at the same time do not increase risk for bleeding. We hypothesize that UFH therapy would be associated with lower rates of thrombosis and higher rates of bleeding in this population.

\section{METHODS \\ Data Collection}

This was a retrospective single-center study of all consecutive pediatric patients younger than age 18 years admitted to our CICU following cardiac surgery between November 2016 and December 2017. Patient data were collected prospectively within the scope of a quality improvement project; therefore, anticoagulation strategy was decided clinically by each attending surgeon and intensivist. Retrospective review of patient data for the purposes of quality improvement project was approved by the Boston Children's Hospital Institutional Review Board.

All medical records were screened for adverse events of thrombosis or bleeding during the patient's stay in the CICU and were reviewed by an adjudication committee of cardiovascular surgeons, intensive care physicians, nurses, and cardiologists. Study data were collected and managed using Research Electronic Data Capture, an electronic data capture tool hosted at Boston Children's Hospital. ${ }^{6}$ Anticoagulation medication was downloaded from an electronic data warehouse. In our center, high-dose UFH consists of $20 \mathrm{U} / \mathrm{kg} / \mathrm{h} \mathrm{UFH}$, whereas a lower maintenance dose of $10 \mathrm{U} / \mathrm{kg} / \mathrm{h}$ is commonly used in order to maintain line patency. All doses and changes of UFH were recorded and for each patient-day UFH doses were classified into 3 groups dependent on the maximum UFH dose for that patient-day. If no UFH was given, the UFH dose was classified as "no UFH", if the highest dose for that patient-day was $>0$ and $<15 \mathrm{U} /$ $\mathrm{kg} / \mathrm{h}$ the UFH dose was classified as "low-dose UFH", and if daily maximum dose was $\geq 15 \mathrm{U} / \mathrm{kg} / \mathrm{h}$ the UFH dose was classified as "highdose UFH." Data collected on UFH therapy on the day of a thrombosis or bleeding event were excluded from analysis because therapy before the event was considered the related therapy. When investigating bleeding or thrombosis, patient-days after the first bleeding or thrombosis, respectively, were excluded from analysis.

\section{Exclusion Criteria}

Patients with a known coagulopathy before CICU admission were excluded from analysis. Patient-days on extracorporeal membrane oxygenation or ventricular assist device were not included in analysis.

\section{Study End Points}

All pediatric patients were followed from admission to discharge in the CICU to determine the incidence of bleeding and thrombosis after cardiac surgery. Thrombosis as well as bleeding remote from procedures of any type (bleeding following cessation of immediate postprocedure bleeding) served as primary outcomes.

With regard to bleeding severity, bleeding events were classified as minor, clinically relevant nonmajor, and major bleeding events. Major bleeding events were defined as bleeding events requiring emergent transfusion of blood products for bleeding with hemodynamic instability or surgical intervention, intracranial hemorrhage, and fatal bleeding events. All bleeding events requiring nonsurgical, medical intervention such as an increase in level of care, laboratory or imaging evaluation, or elective transfusions were classified as clinically relevant nonmajor. All other bleeding events that were neither actionable nor caused unscheduled performance of studies or treatment were classified as minor. For all bleeding events, sudden drops in hematocrit as well as increased chest tube output were taken into consideration. Although we assessed the relationship of all classes of bleeding events, only those remote from surgical procedures were considered primary end points to investigate the association of UFH therapy alone with bleeding. Bleeding events $\leq 36$ hours of admission were only classified as adverse events when bleeding started after the initiation of anticoagulation without initial bleeding following surgery. In addition, bleeding $>36$ hours but related to any other type of procedure such as catheter intervention, line placement, or tracheal tube placement was not classified as a bleeding event.

Thrombosis events were defined as any intravascular thrombosis detected by imaging with or without clinical presentation, or those with major symptomatic clinical findings, which led to changes in clinical management, such as initiation of anticoagulation or surgical intervention as previously defined. ${ }^{7}$ Incidentally discovered thromboses in the peripheral venous system were not included as patients' peripheral veins were not routinely screened.

Adverse events were collected prospectively within the scope of a quality improvement project and therefore discussed within a group of nurses and doctors in charge of patients in the CICU to classify them as adverse event.

Primary outcomes were assessed mutually exclusively. If patients had both a bleeding and thrombosis event, the predictor UFH dose group was determined based on the first occurrence of the event. Both bleeding and thrombosis were recorded as a dichotomous end point (yes or no) for each patient-day.

\section{Statistical Analysis}

We focused on the association between different UFH dosing and bleeding and thrombosis. We categorized the patients without an outcome 
into 3 dosing groups based on the longest duration of UFH dose during the entire stay in the CICU. If a patient was in 2 different dosing categories for the same amount of time, the patient was categorized into the higher-dose group. Patients with a thrombotic event were categorized based on the longest UFH dose duration before the first thrombosis event. Patients with bleeding events were categorized based on the highest UFH dose 24 hours before the first bleeding event. None of the patients received bolus heparin because our protocol for postoperative patients, which has been previously published, does not include bolus for initiation of heparin. ${ }^{8}$

To study the predicted probability of being in a higher category of bleeding severity by UFH dose group, we used a cumulative logit model. With this model, the effect of a particular dose group comparison was the same for any 1-level increase in severity (eg, from none to mild, or from mild to clinically relevant nonmajor, and so on). A score test of the proportional odds assumption was performed to confirm that the logit surfaces were parallel. Logistic regression modeling was used to estimate the association between the outcome and predictors. Age at admission, procedure category and pre-CICU history of thrombosis served as covariates. Age at admission was categorized into 4 groups ( $<1$ mo, $<1$ year, $1-10$ years, and $\geq 10$ years). All surgical procedures were classified into 7 categories. We grouped patients into procedural categories with similar bleeding risk based on preliminary analysis. Therefore, we classified the surgical procedures into minor cardiac procedures, septal defect repairs, vascular repairs, valvular repair, single ventricle surgeries, and repair of ventricular outflow tract obstruction. Minor cardiac procedures included atrial septal defect repair, patent ductus arteriosus ligation, and pulmonary artery banding. Septal defect repair category contained repair of ventricular septal defects, tetralogy of Fallot and complete atrioventricular defect. Arterial switch operation, a repair of total anomalous pulmonary venous return as well as truncus repair were categorized into the vascular repair group. Single ventricle repair contained stage I, stage II, Fontan operation, and biventricular conversion. Valvular repair and repair of ventricular outflow tract obstruction were categorized in separate groups. All procedures that did not fit these categories such as transplants and cardiac tumors were categorized as "Other." The procedural groups were mutually exclusive and patients were categorized into the group with higher risk for an adverse event. Statistical analyses were performed using SAS version 9.4 (SAS Institute Inc, Cary, NC) and R version 3.2. (R Foundation for Statistical Computing, Vienna, Austria).

\section{RESULTS}

A primary cohort of 966 patients younger than age 18 years was followed during their stay in the CICU after cardiac surgery between November 2016 and December 2017 at Boston Children's Hospital. Demographic characteristics of the entire cohort by UFH dose group and age are found in Table 1 and Table 2, respectively. Out of 966 patients, $696(72 \%)$ were treated with UFH at least once during the entire stay in the CICU, whereas 270 patients $(28 \%)$ were never treated with UFH. The percentage of patients who received other medications before bleeding or during CICU stay after surgery for patients who did not have an bleeding event is found in Table 3. Among the entire cohort, 94 patients $(9.7 \%)$ had bleeding and 52 patients $(5.4 \%)$ had thrombosis. Twenty-four bleeding patients experienced the bleeding event within the first 36 hours after surgery. Among patients with bleeding, the percentage of patients who had bleeding within $<36$ hours did not differ by UFH dose group $(39.1 \%$ vs $21.9 \%$ vs $20.5 \%$ for no UFH, low-dose and high-dose UFH, respectively; Fisher exact test $P=.26$ ). Of the 966 patients in our cohort, 341 patients $(35 \%)$ were categorized into the no-UFH group, $401(42 \%)$ into the low-dose UFH group, and 224 patients $(23 \%)$ into the high-dose UFH group during their CICU stay. The high-dose UFH group had the

TABLE 1. Demographic characteristics of the entire cohort by unfractionated heparin (UFH) dose group before first bleeding

\begin{tabular}{|c|c|c|c|c|}
\hline Characteristic & No UFH $(n=341)$ & Low dose $(n=401)$ & High dose $(n=224)$ & $P$ value \\
\hline Age at admission (y) & $6.07 \pm 5.38$ & $2.41 \pm 4.00$ & $2.72 \pm 3.87$ & $<.001$ \\
\hline Median age (y) & $4.46(1.28-10.38)$ & $0.49(0.19-2.73)$ & $0.92(0.08-3.86)$ & $<.001$ \\
\hline Age group & & & & $<.001$ \\
\hline Neonates $(<1 \mathrm{mo})$ & $20(5.9)$ & $66(16.5)$ & $59(26.3)$ & \\
\hline Infant $(<1 \mathrm{y})$ & $54(15.8)$ & $188(46.9)$ & $56(25.0)$ & \\
\hline $1-10 \mathrm{y}$ & $179(52.5)$ & $119(29.7)$ & $93(41.5)$ & \\
\hline$\geq 10 y$ & $88(25.8)$ & $28(7.0)$ & $16(7.1)$ & \\
\hline $\begin{array}{l}\text { History of thrombosis before cardiac intensive care } \\
\text { unit stay }\end{array}$ & & & & $<.001$ \\
\hline Yes & $32(9.4)$ & $26(6.5)$ & $36(16.1)$ & \\
\hline No & $309(90.6)$ & $375(93.5)$ & $188(83.9)$ & \\
\hline Procedure category & & & & $<.001$ \\
\hline 1 Minor cardiac surgeries & $75(22.0)$ & $32(8.0)$ & $15(6.7)$ & \\
\hline 2 Septal defect repair & $33(9.7)$ & $96(23.9)$ & $11(4.9)$ & \\
\hline 3 Structural vascular repair & $24(7.0)$ & $62(15.5)$ & $38(17.0)$ & \\
\hline 4 Valvular surgery & $93(27.3)$ & $71(17.7)$ & $32(14.3)$ & \\
\hline 5 Single ventricle surgery & $32(9.4)$ & $87(21.7)$ & $91(40.6)$ & \\
\hline 6 Ventricular outflow tract obstruction repair & $60(17.6)$ & $45(11.2)$ & $28(12.5)$ & \\
\hline 7 Other & $24(7.0)$ & $8(2.0)$ & $9(4.0)$ & \\
\hline
\end{tabular}

Values are presented as mean \pm standard deviation, median (interquartile range), or $\mathrm{n}(\%)$. Boldface indicates significant results with a level of significance of .05. UFH, Unfractionated heparin. 
TABLE 2. Demographic characteristics of the entire cohort by age group

\begin{tabular}{|c|c|c|c|c|c|c|}
\hline & $\begin{array}{c}\text { Overall } \\
(\mathrm{N}=966)\end{array}$ & $\begin{array}{l}\text { Neonates } \\
(n=145)\end{array}$ & $\begin{array}{c}\text { Infant } \\
(n=298)\end{array}$ & $\begin{array}{c}1 \text { y to }<10 \text { y } \\
(n=391)\end{array}$ & $\begin{array}{c}\geq 10 y \\
(n=132)\end{array}$ & $P$ value \\
\hline $\begin{array}{l}\text { History of thrombosis before cardiac intensive care } \\
\text { unit stay }\end{array}$ & & & & & & .24 \\
\hline Yes & $94(9.7)$ & $8(5.5)$ & $30(10.1)$ & 44 (11.3) & $12(9.1)$ & \\
\hline No & $872(90.3)$ & $137(94.5)$ & $268(89.9)$ & $347(88.7)$ & $120(90.9)$ & \\
\hline Procedure category & & & & & & $<.001$ \\
\hline 1 Minor cardiac surgeries & $122(12.6)$ & $10(6.9)$ & $26(8.7)$ & $63(16.1)$ & $23(17.4)$ & \\
\hline 2 Septal defect repair & $140(14.5)$ & $10(6.9)$ & $110(36.9)$ & $18(4.6)$ & $2(1.5)$ & \\
\hline 3 Structural vascular repair & $124(12.8)$ & $69(47.6)$ & $25(8.4)$ & $26(6.6)$ & $4(3.0)$ & \\
\hline 4 Valvular surgery & $196(20.3)$ & $6(4.1)$ & $43(14.4)$ & $89(22.8)$ & $58(43.9)$ & \\
\hline 5 Single ventricle surgery & $210(21.7)$ & $36(24.8)$ & $66(22.1)$ & $92(23.5)$ & $16(12.1)$ & \\
\hline 6 Ventricular outflow tract obstruction repair & $133(13.8)$ & $11(7.6)$ & $22(7.4)$ & $82(21.0)$ & $18(13.6)$ & \\
\hline 7 Other & $41(4.2)$ & $3(2.1)$ & $6(2.0)$ & $21(5.4)$ & $11(8.3)$ & \\
\hline
\end{tabular}

Values are presented as n (\%). Boldface indicates significant results with a level of significance of .05.

highest proportion of bleeding patients and the highest proportion of thrombosis patients (Figure 1 and Video 1).

\section{Bleeding}

The percentage of patients with bleeding in the no-UFH and low-dose UFH groups were $7 \%$ and $8 \%$, respectively. In the high-dose UFH group, $17 \%$ of patients had bleeding. In unadjusted analysis, patients taking high-dose UFH were more likely to have bleeding than were patients not receiving UFH or low-dose UFH $(P<.001)$. The distribution of bleeding severity among the different UFH dose groups showed that among patients taking high-dose UFH, the percentage of minor and clinically relevant nonmajor bleeding were slightly higher $(5.4 \%$ and $10.7 \%)$ than overall $(3.2 \%$ and $5.2 \%)$.

With regard to patient characteristics, we found that patients with fewer patient-days on UFH therapy were significantly older and were more likely to have undergone a

TABLE 3. Percentage of patients receiving other anticoagulation medications by bleeding status

\begin{tabular}{lccc}
\hline Anticoagulation agent & $\begin{array}{c}\text { All patients } \\
(\mathbf{N}=\mathbf{9 6 6})\end{array}$ & $\begin{array}{c}\text { Bleeding } \\
(\mathbf{n = 9 4 )}\end{array}$ & $\begin{array}{c}\text { No bleeding } \\
(\mathbf{n}=\mathbf{8 7 2})\end{array}$ \\
\hline Lovenox $^{*}$ & $84(8.7)$ & $7(7.4)$ & $77(8.8)$ \\
Plavix $\dagger$ & $5(0.5)$ & $0(0)$ & $5(0.6)$ \\
\hline Aspirin & $676(70.0)$ & $34(36.2)$ & $642(73.6)$ \\
Fondaparinux & $2(0.2)$ & $1(1.1 \%)$ & $1(0.1)$ \\
\hline Coumadin $\dagger$ & $8(0.8)$ & $1(1.1)$ & $7(0.8)$ \\
\hline Argatroban $\dagger$ & $2(0.2)$ & $0(0)$ & $2(0.2)$ \\
\hline Antithrombin $\mathrm{III}$ & $2(0.2)$ & $1(1.1)$ & $1(0.1)$ \\
Tirofiban & $15(1.6)$ & $6(6.4)$ & $9(1.0)$ \\
\hline Bivalirudin & $5(0.5)$ & $1(1.1)$ & $4(0.5)$ \\
\hline
\end{tabular}

*Sanofi, Bridgewater, NJ. †Bristol-Myers Squibb, New York, NY. †Pfizer, New York, NY. minor cardiac surgery $(P<.001)$. We created a propensity score using logistic regression modeling to develop a single adjustment factor for use in modeling. The propensity score represented the predicted conditional probability of each patient receiving a high dose of heparin versus collapsed low-dose-and-no-heparin group, based on the covariates age group, pre-CICU history of thrombosis and procedure category. The propensity score did not discriminate between the 2 groups well: the mean score was $0.32 \pm 0.15$ for the high-dose UFH group and $0.21 \pm 0.13$ for the noand low-dose UFH group. This was likely because there were other determinants of UFH dose that were not included in this dataset. Therefore, we developed a multivariable model by including UFH dose group, age group, pre-CICU history of thrombosis and procedural category as candidates. The model showed that high-dose UFH compared with no UFH and low-dose UFH as well as the younger age group were independently associated with bleeding (Table 4). The dose of heparin among patients with bleeding events $(21.9 \pm 11.2 \mathrm{U} / \mathrm{kg} / \mathrm{h})$ in the highdose UFH group did not significantly differ from those patients who did not develop bleeding among the high-dose UFH group $(21.7 \pm 7.1 \mathrm{U} / \mathrm{kg} / \mathrm{h})(P=.910)$. The cumulative logit model for the predicted probability of being in a higher category of bleeding severity showed that patients receiving high-dose UFH were more likely to have a worse severity of bleeding, whereas there was no increase in risk of being in a more severe bleeding category for patients with low-dose UFH versus no UFH (Table 5).

\section{Thrombosis Events}

Of 52 thrombosis patients in the cohort, 12 patients $(3.5 \%)$ received no UFH, 14 patients $(3.5 \%)$ were taking low-dose UFH, and 26 patients $(11.7 \%)$ were taking high-dose UFH before the thrombosis event. Table 6 displays the thrombosis location sites by UFH dosing group. 


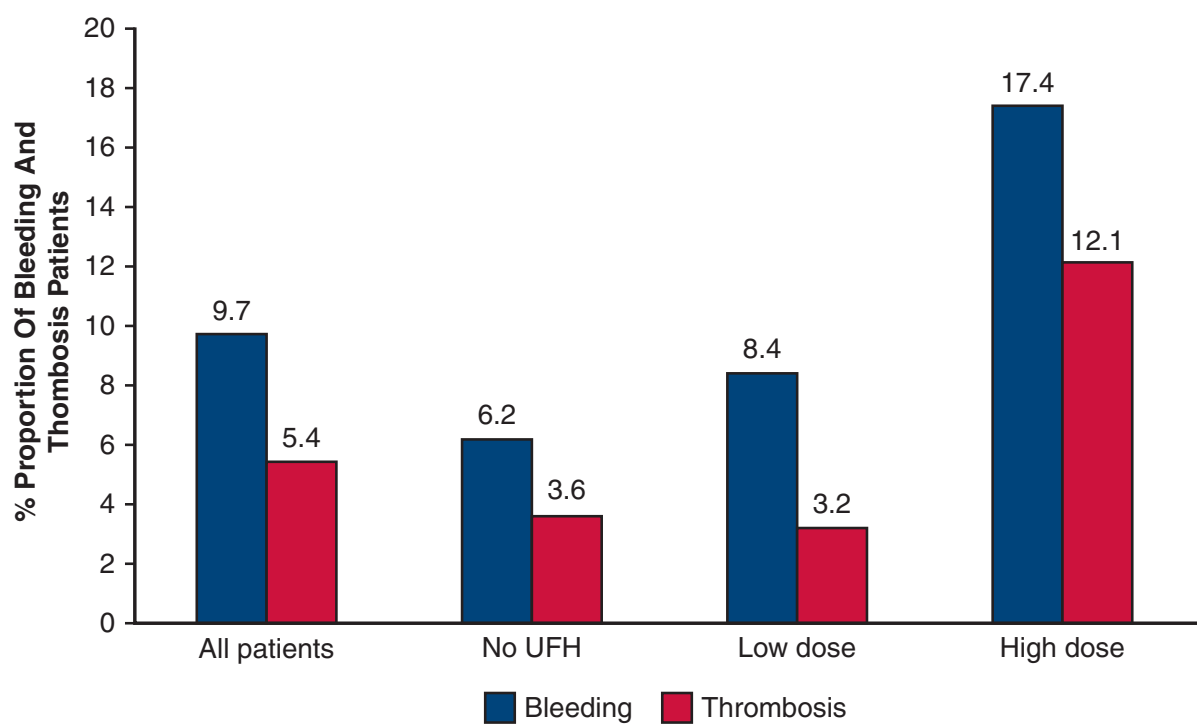

FIGURE 1. Illustrates the outcome of adverse events by unfractionated heparin $(U F H)$ dose group. The high-dose UFH group had the highest proportion of bleeding $(17.4 \%)$ and thrombosis $(12.1 \%)$.

Our unadjusted logistic regression model showed that highdose UFH was significantly related to thrombosis compared with no UFH or low-dose UFH $(P<.001)$. The groups no UFH and low-dose UFH did not differ significantly on the

TABLE 4. Multivariable logistic regression model results for bleeding $(C=\mathbf{0 . 7 2})$

\begin{tabular}{|c|c|c|c|}
\hline Model terms & $\begin{array}{c}\text { Odds ratio }(95 \% \\
\text { confidence interval) }\end{array}$ & $P$ value & $\begin{array}{l}\text { Max- } \\
\text { rescaled } R^{2}\end{array}$ \\
\hline UFH dose group & & .043 & 0.11 \\
\hline No UFH & Reference & & \\
\hline Low dose & $0.77(0.42-1.42)$ & & \\
\hline High dose & $1.52(0.82-2.80)$ & & \\
\hline $\begin{array}{l}\text { High dose vs } \\
\text { low dose }\end{array}$ & $1.97(1.16-3.34)$ & & \\
\hline Age group & & $<.001$ & \\
\hline Neonates $(<1 \mathrm{mo})$ & $8.50(2.65-27.25)$ & & \\
\hline Infant $(<1 \mathrm{y})$ & $4.36(1.41-13.49)$ & & \\
\hline $1-10 y$ & $2.34(0.79-6.96)$ & & \\
\hline$\geq 10 \mathrm{y}$ & Reference & & \\
\hline Procedure category & & .105 & \\
\hline $\begin{array}{l}1 \text { Minor cardiac } \\
\text { surgeries }\end{array}$ & $0.29(0.08-1.09)$ & & \\
\hline 2 Septal defect repair & $0.27(0.08-0.97)$ & & \\
\hline $\begin{array}{l}3 \text { Structural vascular } \\
\text { repair }\end{array}$ & $0.55(0.18-1.72)$ & & \\
\hline 4 Valvular surgery & $0.56(0.18-1.70)$ & & \\
\hline $5 \mathrm{SV}$ surgery & $0.81(0.28-2.36)$ & & \\
\hline 6 VOTO repair & $0.82(0.27-2.51)$ & & \\
\hline 7 Other & Reference & & \\
\hline
\end{tabular}

Boldface indicates significant results with a level of significance of .05. UFH, Unfractionated heparin; $S V$, single ventricle; VOTO, ventricular outflow tract obstruction. odds of thrombosis (odds ratio, $0.98 ; 95 \%$ confidence interval, 0.45-2.14). Younger age, procedure category, and preCICU history of thrombosis were not balanced in the UFH dose groups $(P<.05)$ and that these covariates were confounders of the relationship between UFH dose group and thrombosis $(P<.05)$. After adjusting for these confounders, patients on high-dose UFH had a significantly higher association with thrombosis compared with patients who did not receive UFH (adjusted odds ratio, 2.15; 95\% confidence interval, 1.02-4.53) as well as patients taking low-dose UFH (adjusted odds ratio, 3.65; 95\% confidence interval, 1.81-7.38). The adjusted odds of thrombosis were similar for the low dose and no-UFH groups. Younger age and pre-CICU history of thrombosis were also independently associated with a higher rate of thrombosis (Table 7). The dose of heparin among patients with thrombosis events $(22.2 \pm 6.9 \mathrm{U} / \mathrm{kg} / \mathrm{h})$ in the high-dose UFH group did not significantly differ from those patients who did not develop thrombosis among the high-dose UFH group $(21.0 \pm 7.0$ $\mathrm{U} / \mathrm{kg} / \mathrm{h})(P=.403)$.

\section{DISCUSSION}

Immediate postoperative bleeding in pediatric patients after cardiac surgery is common due to cardiopulmonary bypass and high-risk procedures in the operating room, especially among neonates. ${ }^{9}$ However, bleeding remote from surgery is less common and may be aggravated by aggressive anticoagulation. Pediatric patients are commonly treated with UFH following cardiac surgery to prevent thrombosis, which is associated with increased mortality and morbidity. This study showed a liberal use of UFH in our center with $72 \%$ of patients 
TABLE 5. Multivariable cumulative logit model for severity of bleeding ( $\mathrm{N}=966 ; C=0.72$; max rescaled $R^{2}=0.10$, score test for the proportional odds assumption $P=.07$ )*

\begin{tabular}{|c|c|c|c|}
\hline & Estimate & $\begin{array}{c}\text { Odds ratio }(95 \% \\
\text { Confidence interval) }\end{array}$ & $\begin{array}{c}P \\
\text { value }\end{array}$ \\
\hline Intercept 4 & -5.11 & & \\
\hline Intercept 3 & -3.42 & & \\
\hline Intercept 2 & -2.96 & & \\
\hline $\begin{array}{l}\text { Dose group } \\
\text { Low dose vs no } \\
\text { High dose vs no } \\
\text { High dose vs } \\
\quad \text { low dose }\end{array}$ & $\begin{array}{r}-0.27 \\
0.39 \\
0.66\end{array}$ & $\begin{array}{l}0.76(0.41-1.40) \\
1.48(0.80-2.72) \\
1.94(1.14-3.28)\end{array}$ & .048 \\
\hline $\begin{array}{l}\text { Age group } \\
\text { Neonates }(<1 \mathrm{mo}) \\
\text { Infant }(<1 \mathrm{y}) \\
1-10 \mathrm{y} \\
\geq 10 \mathrm{y}\end{array}$ & $\begin{array}{c}2.15 \\
1.45 \\
0.84 \\
\text { Reference }\end{array}$ & $\begin{array}{l}8.61(2.70-27.39) \\
4.26(1.38-13.13) \\
2.32(0.78-6.85)\end{array}$ & $<.001$ \\
\hline $\begin{array}{l}\text { Procedure category } \\
1 \text { Minor cardiac } \\
\text { surgeries }\end{array}$ & -1.26 & $0.28(0.08-1.07)$ & .092 \\
\hline 2 Septal defect repair & -1.32 & $0.27(0.07-0.96)$ & \\
\hline $\begin{array}{l}3 \text { Structural vascular } \\
\text { repair }\end{array}$ & -0.57 & $0.57(0.18-1.76)$ & \\
\hline 4 Valvular surgery & -0.59 & $0.55(0.18-1.69)$ & \\
\hline $\begin{array}{l}5 \text { Single ventricle } \\
\text { surgery }\end{array}$ & -0.17 & $0.84(0.29-2.41)$ & \\
\hline $\begin{array}{l}6 \text { Ventricular outflow } \\
\text { tract obstruction } \\
\text { repair }\end{array}$ & -0.21 & $0.81(0.27-2.45)$ & \\
\hline 7 other & Reference & & \\
\hline
\end{tabular}

Boldface indicates significant results with a level of significance of .05. *History of thrombosis before cardiac intensive care unit stay $P=.61$ when added to this model.

receiving UFH at least once during their postoperative CICU stay. It also showed an association between use of high-dose UFH and postoperative thrombosis, but no association between low-dose UFH treatment and thrombosis.

Guidelines for UFH therapy following cardiac surgery have not been established, and it has been shown that incidence of bleeding events among pediatric patients receiving UFH ranges from $2 \%$ to $28 \%$, with major bleeding complications occurring in $11 \%$ of these patients. ${ }^{10-13}$ In our study, incidence of bleeding remote from surgery was $10 \%$ among the entire patient cohort. One problem in UFH therapy is the determination of therapeutic and yet safe dosing levels for pediatric patients after cardiac patients. Because laboratory testing cannot guarantee a therapeutic or subtherapeutic level of UFH because data is based on adult studies, this study sought to look at different UFH dosing groups. This analysis revealed that high-dose UFH cohort demonstrated highest risk of bleeding, a result consistent with previous findings. ${ }^{14}$
Known risk factors for bleeding and thrombosis, including neonatal age at surgery and single ventricle physiology were analyzed to reduce effects of these confounders. ${ }^{1}$

After adjusting for multiple confounders, the study demonstrated an association between high-dose UFH therapy and higher bleeding and thrombosis rates when compared with low-dose and no UFH. Furthermore, patients receiving low-dose UFH had similar odds of developing thrombosis and bleeding compared with patients who did not receive UFH therapy. Patients on high-dose UFH were more likely to experience worse bleeding complications compared with patients taking low-dose or no UFH. These results suggest that high-dose UFH may be ineffective for thrombosis prophylaxis following cardiac surgery while having a significantly higher association with bleeding events. Conversely, low-dose UFH may be as effective as high-dose UFH in terms of thromboprophylaxis with a significantly lower rate of bleeding events. These findings are consistent with the results of a randomized control trial comparing low-dose and high-dose UFH therapy in pediatric patients after cardiac catheterization in which the incidences of bleeding and thrombosis did not differ among the 2 groups. It also suggested that lowdose UFH could be sufficient for prevention of thrombosis following cardiac catheterization. ${ }^{15}$ High-dose UFH use following cardiac surgery should be evaluated carefully in pediatric patients who are at increased risk for bleeding and thrombosis events.

In our study, $5.4 \%$ of patients had thrombosis during their stay in the CICU after cardiac surgery. A recent study demonstrated that $17 \%$ to $24 \%$ of thrombi in pediatric patients following heart surgery result in serious complications. ${ }^{7,16}$ In addition, risk factors for thrombosis detected in this study included previous history of thrombosis and neonatal age group. These risk factors have been previously found to be associated with increased risk of perioperative thrombosis in pediatric patients. Surprisingly, use of high dose UFH was associated with significantly higher rates of thrombosis compared with patients not receiving UFH. Although our multivariable analysis attempted to correct for confounding variables, selection bias may have resulted in detection of an association between high-dose UFH and thrombosis in that high-dose UFH is a marker for patients at higher risk for thrombosis. Other investigators have shown that heparin does not prevent thrombosis in patients with intravascular prosthetic material, consistent with the low incidence of thrombosis seen in patients receiving low-dose or no-dose UFH group in our study. ${ }^{17}$

Monitoring of UFH dose is challenging especially in younger pediatric patients. Mitchell and colleagues ${ }^{10}$ showed in a prospective cohort study that there is little correlation between aPTT, Anti-Xa, and UFH dose, which 
TABLE 6. Thrombosis sites by different unfractionated heparin (UFH) dose groups

\begin{tabular}{|c|c|c|c|c|c|c|}
\hline Thrombosis & All patients & No UFH & Low dose & High dose & Fisher $P$ value & MH $P$ value \\
\hline Thrombosis & 52 & 12 & 14 & 26 & & \\
\hline Venous central & & & & & .866 & .968 \\
\hline No & $33(63.5)$ & $8(66.7)$ & $8(57.1)$ & $17(65.4)$ & & \\
\hline Yes & $19(36.5)$ & $4(33.3)$ & $6(42.9)$ & $9(34.6)$ & & \\
\hline Stroke & & & & & .054 & .051 \\
\hline No & $48(92.3)$ & $9(75.0)$ & $14(100)$ & $25(96.2)$ & & \\
\hline Yes & $4(7.7)$ & $3(25.0)$ & $0(0)$ & $1(3.8)$ & & \\
\hline Shunt thrombosis & & & & & .596 & .889 \\
\hline No & $49(94.2)$ & $11(91.7)$ & $14(100)$ & $24(92.3)$ & & \\
\hline Yes & $3(5.8)$ & $1(8.3)$ & $0(0)$ & $2(7.7)$ & & \\
\hline Arterial, central & & & & & .190 & .064 \\
\hline No & $37(71.2)$ & $11(91.7)$ & $10(71.4)$ & $16(61.5)$ & & \\
\hline Yes & $15(28.8)$ & $1(8.3)$ & 4 (28.6) & $10(38.5)$ & & \\
\hline Right atrium & & & & & .050 & .026 \\
\hline No & $50(96.2)$ & $10(83.3)$ & $14(100)$ & $26(100)$ & & \\
\hline Yes & $2(3.8)$ & $2(16.7)$ & $0(0)$ & $0(0)$ & & \\
\hline Line thrombosis & & & & & .212 & .895 \\
\hline No & $42(80.8)$ & 11 (91.7) & $9(64.3)$ & $22(84.6)$ & & \\
\hline Yes & $10(19.2)$ & $1(8.3)$ & $5(35.7)$ & $4(15.4)$ & & \\
\hline Extremity, arterial & & & & & 1.000 & .895 \\
\hline No & $42(80.8)$ & $10(83.3)$ & $11(78.6)$ & $21(80.8)$ & & \\
\hline Yes & $10(19.2)$ & $2(16.7)$ & $3(21.4)$ & $5(19.2)$ & & \\
\hline Fontan baffle & & & & & 1.000 & .368 \\
\hline No & $51(98.1)$ & $12(100)$ & $14(100)$ & $25(96.2)$ & & \\
\hline Yes & 1 (1.9) & $0(0)$ & $0(0)$ & $1(3.8)$ & & \\
\hline
\end{tabular}

Boldface indicates significant results with a level of significance of .05. UFH, Unfractionated heparin; $M H$, Mantel-Haenzel.

emphasizes the difficulty in monitoring anticoagulation with UFH. ${ }^{10}$ Based on a previous study, our center utilizes a combination of PTT and anti-Xa levels to adjust UFH dosing. ${ }^{17,18}$ Modifications of high dose goals may reduce the risk of bleeding in patients undergoing therapy with high-dose UFH.

\section{Limitations}

The definition of bleeding utilized in this study was adapted from previous studies in the literature. ${ }^{17}$ Nevertheless, a limitation of this study includes the relative subjectivity of definition of bleeding. There was no standardized screening for thrombosis events and events were only

TABLE 7. Multivariable logistic regression model results for thrombosis $(C=0.77)^{*}$

\begin{tabular}{|c|c|c|c|}
\hline Variable & Odds ratio $(95 \%$ confidence interval $)$ & $P$ value & Max-rescaled $R^{2}$ \\
\hline Unfractionated heparin dose group & & .001 & 0.13 \\
\hline No unfractionated heparin & Reference & & \\
\hline Low dose & $0.59(0.26-1.35)$ & & \\
\hline High dose & $2.15(1.02-4.53)$ & & \\
\hline High dose vs low dose & $3.65(1.81-7.38)$ & & \\
\hline History of thrombosis before cardiac intensive care unit stay & & .003 & \\
\hline Yes & $2.98(1.44-6.16)$ & & \\
\hline No & Reference & & \\
\hline Age group & & $<.001$ & \\
\hline Neonates $(<1 \mathrm{mo})$ & $8.19(1.76-38.09)$ & & \\
\hline Infant $(<1 \mathrm{y})$ & $5.55(1.23-25.06)$ & & \\
\hline $1-10 y$ & $1.84(0.40-8.48)$ & & \\
\hline$\geq 10 \mathrm{y}$ & Reference & & \\
\hline
\end{tabular}

Boldface indicates significant results with a level of significance of .05 . *Procedure category has $P=.42$ when added to this model. 


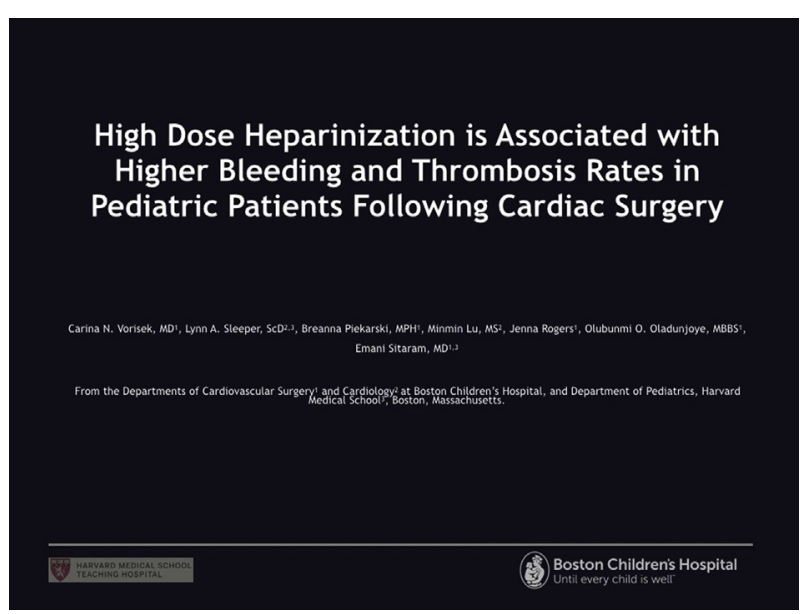

VIDEO 1. The video shows the first author pointing out the most important findings of this study. Video available at: https://www.jtcvs.org/ article/S0022-5223(19)31211-5/fulltext.

captured when clinically relevant or diagnosed during standard imaging for other clinical indications. The lack of standardized ultrasound screening might also have led to an underestimation of thrombosis incidence. Because capturing the exact time of thrombosis remains challenging with this approach, we analyzed UFH therapy over time up to the event. Furthermore, this was an observational study in 1 center only. Our results of higher thrombosis events in the high-dose UFH group could be due to other risk factors that were not included in analysis such as previous procedures, previous extracorporeal membrane oxygenation cannulation, and previous surgical complications. Additional anticoagulation medications besides UFH were not taken into account in this analysis. However, aspirin was the only anticoagulation medication with use not balanced between patients with and without outcomes of bleeding or thrombosis. Patients without bleeding or thrombosis were more likely to be taking aspirin and therefore aspirin was not analyzed as a potential risk factor for our study end points (ie, bleeding and thrombosis).

\section{CONCLUSIONS}

High-dose UFH is associated with a higher rate of bleeding and a higher likelihood of more severe bleeding in patients following cardiac surgery. High-dose UFH is not associated with a lower rate of thrombosis when compared with lowdose and no UFH in this specific patient population. A reappraisal of the risk and benefits of high-dose UFH use in pediatric patients postcardiac surgery is warranted. Guidelines for UFH strategy in pediatric cardiac patients, as well as new anticoagulation medications, need to be further assessed to reduce bleeding risk during thrombosis prophylaxis.

\section{Conflict of Interest Statement}

Authors have nothing to disclose with regard to commercial support.

\section{References}

1. Giglia TM, Massicotte MP, Tweddell JS, Barst RJ, Bauman M, Erickson CC, et al. Prevention and treatment of thrombosis in pediatric and congenital heart disease: a scientific statement from the American Heart Association. Circulation. 2013;128:2622-703.

2. Manlhiot C, Menjak IB, Brandão LR, Gruenwald CE, Schwartz SM, Sivarajan VB, et al. Risk, clinical features, and outcomes of thrombosis associated with pediatric cardiac surgery. Circulation. 2011;124:1511-9.

3. Boris JR, Harris MA. The use of anticoagulation in pediatric cardiac disease. Images Paediatr Cardiol. 2003;5:1-35.

4. Ignjatovic V, Summerhayes R, Than J, Gan A, Monagle P. Therapeutic range for unfractionated heparin therapy: age-related differences in response in children. $J$ Thromb Haemost. 2006;4:2280-3.

5. Monagle P, Chalmers E, Chan A, deVeber G, Kirkham F, Massicotte P, et al. Antithrombotic therapy in neonates and children. Chest. 2008;133:887S-968S.

6. Harris PA, Taylor R, Thielke R, Payne J, Gonzalez N, Conde JG. Research electronic data capture (REDCap) - a metadata-driven methodology and workflow process for providing translational research informatics support. J Biomed Inform. 2009;42:377-81.

7. Emani S, Trainor B, Zurakowski D, Baird CW, Fynn-Thompson FE, Pigula FA, et al. Aspirin unresponsiveness predicts thrombosis in high-risk pediatric patients after cardiac surgery. J Thorac Cardiovasc Surg. 2014;148:810-6.

8. Nair AG, Oladunjoye OO, Trenor CC, LaRonde M, van den Bosch SJ, Sleeper LA, et al. An anticoagulation protocol for use after congenital cardiac surgery. J Thorac Cardiovasc Surg. 2018;156:343-52.

9. Williams GD, Bratton SL, Riley EC, Ramamoorthy C. Association between age and blood loss in children undergoing open heart operations. Ann Thorac Surg. 1998;66:870-5.

10. Mitchell LG, Kuhle S, Massicotte PM, Vegh P. Increased incidence of major bleeding in children receiving unfractionated heparin for clinical management: a prospective cohort study. Blood. 2004;104:1772.

11. Schechter T, Finkelstein Y, Ali M, Kahr WH, Williams S, Chan AK, et al. Unfractionated heparin dosing in young infants: clinical outcomes in a cohort monitored with anti-factor Xa levels. J Thromb Haemost. 2012;10:368-74.

12. Kuhle S, Eulmesekian P, Kavanagh B, Massicotte P, Vegh P, Mitchell LG. A clinically significant incidence of bleeding in critically ill children receiving therapeutic doses of unfractionated heparin: a prospective cohort study Haematologica. 2007;92:244-7.

13. Andrew M, Marzinotto V, Massicotte P, Blanchette V, Ginsberg J, BrillEdwards $\mathrm{P}$, et al. Heparin therapy in pediatric patients: a prospective cohort study Pediatr Res. 1994;35:78-83.

14. Dabbous M, Malaeb D, Sakr F. Anticoagulant therapy in pediatrics. J Basic Clin Pharm. 2014;5:27.

15. Hanslik A, Kitzmüller E, Thom K, Haumer M, Mlekusch W, Salzer-Muhar U, et al. Incidence of thrombotic and bleeding complications during cardiac catheterization in children: comparison of high-dose vs. low-dose heparin protocols. $J$ Thromb Haemost. 2011;9:2353-60.

16. Manlhiot C, Brandão LR, Schwartz SM, Sivarajan VB, Williams S, Collins TH, et al. Management and outcomes of patients with occlusive thrombosis after pediatric cardiac surgery. J Pediatr. 2016;169:146-53.

17. Schroeder AR, Axelrod DM, Silverman NH, Rubesova E, Merkel E, Roth SJ. A continuous heparin infusion does not prevent catheter-related thrombosis in infants post cardiac surgery. Pediatr Crit Care Med. 2010; 11:489-95.

18. Oladunjoye OO, Sleeper LA, Nair AG, Trenor CC III, VanderPluym C, Kheir JN, et al. Partial thromboplastin time is more predictive of bleeding than anti-Xa levels in heparinized pediatric patients following cardiac surgery. J Thorac Cardiovasc Surg. 2018;156:332-40.

Key Words: anticoagulation, heparin, bleeding, thrombosis, congenital heart disease 